\title{
Hvorfor notationel ikonicitet er en form for operationel ikonicitet
}

\section{Sybille Krämer}

\section{Det fonografiske dogme}

Hvad betyder 'inskription'? Få spørgsmål forekommer lettere at besvare: en inskription er sprog, som er blevet nedskrevet. Den holder det talte ords flygtighed på afstand og befrier kommunikation fra talens ansigt-til-ansigt-forankring. Det skrevne ord overfører den akustiske sekvens til en visuel konfiguration; det udvider kommunikationen over afstande i tid og rum. At forvandle det talte til det skrevne muliggør ligeledes kontrol, rettelser og kritik, ligesom det åbner for spredning og arkivering af det der kommunikeres som tekst.

Det var nøjagtig debatten omkring 'mundtlighed og skriftlighed' (Goody 1968, 1986; Havelock 1976, 1986; Ong 1982)1 i den sidste tredjedel af det forgangne århundrede, som afdækkede skriftens kreativitet og hævede det skrevne ord til det samme niveau som det talte. Siden da er det talte og det skrevne ord blevet betragtet som to forskellige former for sprog, hver med sin egen 'performance profil' i relation til deres mediale, sprog-

1 Se også Finnegan 1973; Falck 1990. Overordnet om debatten: Krämer 200 5a. 
lige, og kulturelantropologiske karakter (Echlich 1994; Koch/ Oesterreicher 1985, 1994; Olson 1991; Parry 1971; Raible 1991, 1993; Zumthor 1984).

På trods af denne genopdagelse af skriftlighed, er en traditionel antagelse - nærmest en vedtaget sandhed i debatten om skriftlighed - forblevet uudfordret: Troen på skriftens sproglignende karakter. I forbindelse med den almindelige tvedeling mellem sprog og billede, placeres skriften udelukkende inden for sprogets felt. Skrift fortolkes som en form for sprog og ikke som en form for billede. Den i mellemtiden klassiske håndbog Schrift und Schriftlichkeit. Writing and its use (Günther/Ludwig (red.) 1994), opsummerer udfaldet af skriftlighedsdebatten og definerer skrift som "den mængde af skriftlige tegn gennem hvilken et talt sprog optegnes" (Günther/Ludwig (red.) 1994: VIII.; Koch 2009: 58). Vi vil kalde det synspunkt at skrift først og fremmest er en fikseret version af et talt sprog for det fonografiske dogme (Krämer 2003b: 520).

\section{Tre blinde pletter ved et tale-centreret skriftbegreb:}

Det er muligt at afdække tre blinde pletter ved det tale-orienterede skriftbegreb:

(1) Antagelsen at skrift refererer til tale:

Det antikke græske alfabet understøttede aldrig teorien om at alfabetet udelukkende refererer til talens lyde, for vi ved i dag at de græske bogstaver ikke kun refererede til ord men også til tal og til musikalske toner (Kittler 2003: 198-200; Ernst/Kittler (red.) 2006). Eller tænk på opfindelsen af moderne, symbolsk algebra, hvis konstituerende tegn består af alfabetiske bogstaver, som hverken refererer til talens lyd eller til tal, men snarere til strukturelle former i almenhed. Desuden er alfabetets succes også forankret $\mathrm{i}$ tegnenes organisatoriske potentiale, ${ }^{2}$ som har vist sig at være det ideelle instrument til at opnå en præcis sortering af alle typer af lister, ordbøger, telefonbøger osv. (Günther

\footnotetext{
2 O.A. I originalen skriver Krämer her om de " 26 tegns organisatoriske potentiale", men da dette antal dels skurrer i den skandinaviske læsers ører, og Krämers pointe desuden relaterer sig til den generelle alfabetiske organisering (som f.eks. også er gældende for det græske og det kyrilliske alfabet) og ikke specifikt til det latinske alfabet, har jeg valgt at udelade antallet i oversættelsen.
} 
1994). Eller overvej den sproglige funktion af tegn som punktummer, tankestreger, parenteser og operationelle tegn, som ikke har nogen ækvivalent i det talte sprog. Koreografi var også et vigtigt medium for udviklingen af moderne dans, ligesom musikalske noder har været vigtige for udviklingen af den vestlige verdens musik. Matematik og logik ville være utænkelige uden notationssystemer. Computeren ville være utænkelig uden programkode, ligesom digitalisering er forankret i det binære alfabet. Det er således tydeligt at skrift ikke er et sekundært system som refererer til det talte sprog som sit primære system. Snarere er det et enestående symbolsk system, som kun lejlighedsvis refererer til mundtlig tale.

(2) Antagelsen af linearitet som et strukturerende princip for skrift:

Teorien om skriftens linearitet er en anden problematisk, for ikke at sige fejlagtig, antagelse, som det tale-centrerede skriftbegreb fører med sig. Det talte ords fremdrift danner en tidslig rækkefølge, og det antages at denne endimensionelle følgestruktur overføres til den rumlige organisering af skrevne tegn. Linearitetsprincippet fra det talte sprog erklæres således også for skriften. Men selvom både det at skrive og det at læse er aktiviteter der udspiller sig i tid, så gør skriften altid brug af overfladens todimensionalitet, og dens samtidighed eller synkronisitet (Groß 1990: 236-238). I alle former for skrift - også fonetisk skrift - struktureres konfigurationen horisontalt, idet linjerne fortsætter mod enten højre eller venstre, så vel som vertikalt fra top til bund eller for nogle få undtagelsers vedkommende fra bund til top. Denne skriftens todimensionelle matrice har ingen ækvivalent i mundtlig tale; således er skriften tydeligvis ikke lineær (Harris 1990: 39).

(3) Reduktionen af skrift til den grundlæggende kommunikative funktion.

Når skriften nedfælder det talte ord, overtager den talens kommunikative funktion. Men skriften er desuden det ideelle værktøj, ikke alene til kommunikation som er udvidet i tid eller rum, men også til kognition. Skriften er en form for tankeredskab. Overvej for eksempel skrevne udregninger som gør det mu- 
ligt at løse regneproblemer gennem applikationen af algoritmer som arrangerer og omrokerer de skrevne symboler. Videnskabsfolks notesbøger og sågar romanforfatteres, viser ligeledes hvordan inskriptioner tjener som medium, der muliggør den gradvise udvikling af tanker og overbevisninger. Skrift fremmer således eksternaliseringen, selvobservationen og kontrollen af tænkning og kognition. Skriftens rum udgør et tankelaboratorium.

Ideen om at skrift er en form for sprog, og at den strukturelle organisering af skrift er afledt af den lineære organisering af talen, rammer således helt ved siden af. Men hvad er alternativet?

\section{At overvinde det fonografiske dogme}

I løbet af de seneste årtier er forskellige fremgangsmåder blevet udviklet til at overvinde det fonografiske dogme. Det er blevet kritiseret og stillet spørgsmål til på mange forskellige måder, hvoraf seks skal nævnes her:

(1) Ikke-alfabetisk og ikke-europæisk skrifts rolle som politisk magt-, organisations-, kommunikations- og tænkningsmiddel er blevet undersøgt (Jan Assmann 1992; Gong 2009; Wilcke 2000).

(2) Brugen af notation i naturvidenskaberne, matematikken og logikken er blevet studeret, hvilket har afdækket at videnskab ville være umulig uden visuelle markeringer som skrift, tabeller og diagrammer (Hoffmann 2010, 2008; Klein 2003; Mersch 2005; Rheinberger 1999).

(3) Inden for litteraturvidenskaben er skriftens scene og litteraturens grafiske dimension blevet studeret (Campe 1991; Giuriato/Kammer 2006; Giuriato/Stingelin 2008; Raible 2004; Stingelin 1999; Zanetti 2012), inden for musikvidenskab er forskning i notation og kladder blevet stadig vigtigere (Magnus 2011), og i dansevidenskab er fokus skiftet til koreografiens notationsformer (Brandstetter et al. 2010).

(4) Antikke kulturstudier og klassisk filologi har rekonstrueret både skriftlige dokumenters materialitet, som en særlig orden af virkelige genstande, og de praksisformer som afhænger af brugen af inskriptioner (Cancik-Kirschbaum 2005; Damerow 1993; Schmandt-Besserat 1992). 
(5) Computeren er blevet anerkendt som skriftmaskine, og skriftens rolle som basis for digitalisering og programmering på den ene side og internetkommunikation på den anden side er blevet diskuteret (Bolter 1991, 1997, 2005; Grube 2005).

(6) De ideografiske elementer i udviklingen af skriften er blevet understreget. Lad mig kort adressere dette vigtige aspekt af ideografien. I skriftlige kilder som går tilbage til det græske alfabet kan det observeres at de oprindeligt bestod af kæder af bogstaver som knap nok kunne dechifreres med mindre de blev læst som lyd. Over tid er grænserne mellem ord blevet markeret ved hjælp af mellemrum; tegnsætning, kapiteloverskrifter, afsnitsinddelinger, fodnoter osv. er også blevet introducerede for at gøre tekster lettere at læse og for at forstå deres syntaktiske og semantiske struktur. Dog har ingen af disse elementer ækvivalenter på det talte sprogs akustiske niveau. Disse aspekter er ikke fonetiske, men snarere ideografiske, og disse ideografiske aspekter repræsenterer ikke det talte sprog selv. Det er således tydeligt at selve udviklingen af alfabetisk skrift allerede tenderer mod at inkorporere dimensioner i sit skriftbillede, som er uafhængige af og neutrale i forhold til det talte sprog (Raible 1991, 2009; Krämer 2005).

For at opsummere indtil videre: det fonografiske dogme og skriftbegrebet som fokuserer på mundtlig tale er blevet kritiseret på mange måder. Alligevel er der aldrig blevet skabt en teoretisk konsolidering af disse forskellige tilgange eller en systematisk udvikling af et generelt, fonetisk neutralt skriftbegreb som sammenknytter alfabetiske og ikke-alfabetiske, matematiske, logiske, musikalske, koreografiske og digitale former for skrift. Det er præcis på dette punkt at begrebet 'notationel ikonicitet' er relevant, idet det definerer et perspektivskifte fra et taleorienteret til et taleuafhængigt skriftbegreb. Begrebet 'notationel ikonocitet' sigter på at tilvejebringe en kritisk revision af det fonografiske såvel som det alfabetcentrerede skriftbegreb. De følgende refleksioner forsøger at indramme dette anderledes skriftbegreb. ${ }^{3}$

3 Begrebet 'notationel ikonicitet' er introduceret i Krämer 2003, 2012, og undersøgt fra forskellige disciplinære perspektiver i Krämer/Giertler 2011 og Krämer 


\section{Notationel ikonicitet}

Begrebet 'notationel ikonicitet' sigter på at revidere det sprogafhængige skriftbegreb. En skreven tekst tæller ikke længere som 'rent' sprog, men som en hybrid mellem sprog og billede. Det afgørende punkt her er at skriftens specifikke potentiale - for så vidt som det rækker ud over kommunikation i tid og rum alene kan forstås fyldestgørende når vi betragter dets implicitte ikonicitet.

Talen om 'notationel ikonicitet' drejer sig om en form for ikonicitet som er iboende i næsten alle ${ }^{4}$ skrevne tekster og som baserer sig på det faktum at skrevne tekster er materielt og perceptionsmæssigt indskrevne $\mathrm{i}$ et todimensionelt rum, som de udnytter og som - uafhængigt af den primært lineære skrive- og læseproces - præsenterer sig visuelt overskueligt og simultant for deres betragter og læser. Det skrevne deler sine visuelle og todimensionelle attributter med almindelige billeder, men afviger alligevel fra disse - og forbinder sig til sproget ved at inkarnere en form for organiseret tegnsystem som er både distinkt og syntaktisk. I kraft af denne relation mellem det billedlige og det sproglige, skaber skriften et operationelt felt, som endnu ikke har et forbillede hverken i det billedlige eller i det sproglige: nemlig det grafiske mediums potentiale til at udforme og transformere tegnstrukturer kreativt og udforskende på måder som lader sig reproducere.

Dette er hvad vi ønsker at kalde for 'operativ ikonicitet'. Denne operativitet ${ }^{5}$ finder sted når skrivningen af tekster forvandler sig til et laboratorium for deres forfattere i udfoldelsen af deres egne tanker; hvor komponister komponerer musik med hjælp fra nodeblade; hvor matematiske problemer løses med papir og blyant, hvor en programmør konstruerer algorit-

et al. 2012.

4 Undtagelse: Braille osv.

5 OA: Selvom “operativitet” ikke er et gængst ord på dansk, har jeg valgt at benytte det som oversættelse af det engelske "operativity", frem for det umiddelbart lidt mere mundrette (men stadig let kluntede) "operationalitet" for at bevare Krämers skelnen mellem det engelske "operational" og "operative" og afledninger af disse, hvor "operativ" i min oversættelse beskriver et fænomens (skriftens) disponering for tænkning og handling, fx i løsningen af et matematisk problem, mens "operationel" mere overordnet kan beskrive den praktiske omsætning af et teoretisk begreb. 
merne til en kompleks operation som er læselig for maskiner, hvor et tryk på en knap på et computertastatur aktiverer et link som åbner et website. Det skrevne udtryk bliver et produktivt redskab og et undersøgelsesinstrument til at gøre noget, som ikke ville være muligt eller i hvert fald ville være meget vanskeligt at udføre uden. Det skrevne ord repræsenterer altså ikke bare noget, det skaber også det repræsenterede - i større eller mindre grad.

Almindeligvis bruger vi visualitet til at definere ikonicitet. Men - og dette er omdrejningspunktet i vores argumentation - det er ikke bare skrifttegnenes visualitet, men i stedet deres spatialitet som har betydning i denne sammenhæng. Et tredimensionelt rum omgiver os. Men skrevne tekster trækker på en anden form for rumlighed: det todimensionelle rum. Billeder står således i kontrast til skulptur og arkitektur: de er flade. De deler denne fladhed med andre visuelle artefakter såsom grafer, diagrammer, kort - og skrift. Opfindelsen af 'kunstig fladhed' 6 transformerer overfladen på en hvilken som helst fyldig gestalt til en 'overfalde uden dybde', som kun er vigtig i kraft af hvad som er indskrevet på den. Fra hulemalerier og tatoveringer, over bemalede lærreder og trykte sider, til computerskærmen og smartphonen kan vi efterspore et kulturelt fænomen: Håndteringen af flader dækket med billeder, tegn og beskrivelser. Der eksisterer en "udfladningens" kulturteknik (Krämer 2014: 6) som udgør en vigtig streng i vores medieudvikling. Dens relevans er åbenbar: vores livsverden er altid situeret i et rum som relaterer sig til et bagved eller et under, som er skjult for vores blik, og det er denne usynlige og ukontrollerbare dimension som ophæves af kunstig fladhed. Hvis noget projiceres og indskrives på en overflade bliver betragteren og læseren omflyttet til at indtage et fugleperspektiv: et rum opstår som er fuldstændig kontrollerbart og - i det tilfælde at det har en begrænset udstrækning - umiddelbart kan transporteres. Resultatet er samtidighed og overblik, det vigtige potentiale ved den kommunikative og kognitive organisering.

6 Vedrørende fladhed som et medium for det billedlige, se Summers 2003. 


\section{Spatialitet}

Det bliver nu tydeligt hvorfor det fonografiske skriftbegreb er for snævert. Så længe forholdet mellem et talt og et skrevet sprog betragtes som et oversættelsesforhold er skriften underlagt sekventialitetens regime. Den akustiske lydsekvens overføres til den visuelle sekvens af bogstaver og ord, og lineariteten bliver således det organiserende princip. Dette sekventielle udgangspunkt savner imidlertid den operative betydning som er indeholdt $\mathrm{i}$ det skrevne tegns simultanitet. Der hersker ingen tvivl om at skrift og læsning er tidslige processer, mens tekster - som allerede etymologisk antyder en vævet tekstiloverflade - benytter to dimensioner. De udfolder sig ikke kun på lineær vis fra højre mod venstre (og vice versa), men benytter sig også af forskellen mellem foroven eller forneden. Skriftlige spil, såsom krydsord og sudoko, er de mest træffende demonstrationer af dette. Men også den måde hvorpå den videnskabelige tekst er distribueret $i$ brødtekst og fodnoter, måden matematiske beregninger laves på - hvor tal manipuleres under hinanden - og måden hvorpå musikalsk notation angiver samklangen af instrumenter på et nodeblad, viser hvordan den diakrone linearitet brydes op til fordel for en synkron rumlighed.

Hvad der adskiller skrevne tekster fra akustiske lydstrømme er således nøjagtig ophævelsen af linearitetsprincippet (Harris 1990: 39; Groß 1990: 238) - hvilket præcis er hvad som forbinder dem med alle former for billeder. Hvad der adskiller skrevne tekster fra normale billeder og fotografier er deres mellemrumlighed (Zwischenräumlichkeit): de behøver tomme pladser og mellemrum for at være visuelt aflæselige og operativt håndterbare som konfigurationer. En skreven tekst er afhængig af at have elementerne i sit tegnrepertoire til at fremstå organiseret i rumlige planer. Det skrevne er en konfiguration som kan formes og transformeres, en differentialitet som kan struktureres og som omstrukturerer på en semantisk produktiv måde. Elementernes rumlige placering bidrager til betydning og mening. Tænk på fodnoter, indholdsfortegnelser, titler og indekser, noder i musik - eller se på tallene i titallets positionssystem, hvor værdien af et ciffer afgøres af dets position i det numeriske 
udtryk. Hvad der bliver åbenbart er, at den rumlige placering ofte udgør, eller i det mindste fremkalder, betydningen af noget skrevet.

Deres egenskab af disjunktivt 'ordningsmønster' (Anordnung) (Cancik-Kirschbaum/Mahr 2005) adskiller skrevne tekster fra talesprog. Når vi taler, arrangerer vi ikke fonemerne, vi holder ikke pauser mellem vores ord og sætninger. Den teknologiske optagelse af mundtlig tale viser et ophold når taleren skal have vejret, men disse ophold korresponderer ikke med den syntaktiske ordning af det talte. Tale er strøm, et næsten kontinuerligt akustisk flow. At opdele den akustiske strøm i fonemer har intet fysisk fundament (Coulmas 1993: 192, Coulmas 1981). Fonemet som sproglig enhed er en projektion af grafemet (Lüdtke 1969; Klein 1985). Det særskilte tegn isolerer ikke blot grafemerne fra hinanden, det introducerer også grammatisk forskel i form af store og små bogstaver og tegnsætning, hvoraf intet genfindes i det talte sprogs flux. Heri ligger årsagen til at skriftsprog ikke kan være en imitation af det mundtlige. Modsat, det skrevne tegn tilbyder en kartografi over sprog, det gør sprog observerbart og designer sprog som et uafhængigt semiotisk system, løsrevet fra mimik, gestik, prosodi og situeret deiksis.

\section{Et eksempel}

Følgende eksempel demonstrerer hvad det betyder at den rumlige relation fungerer som medium og miljø for skriften, som en form for tænkning (Hayes 2006). Det er en anekdote om matematikeren Carl Friedrich Gauss som barn. En lærer stiller klassen den opgave at beregne summen af de første 100 naturlige tal. Den 9-årige Gauss præsenterer det korrekte svar '5050' efter kun fem minutters arbejde. Det er ikke vanskeligt at forklare hans elementære princip: Løsningen afhænger af en manipulering af den rumlige organisering af de skrevne tal via operationer som grupperer og omgrupperer den sekventielle orden af numre.

Således kan rækkefølgen af de første 100 naturlige tal skrives som følger: 


\section{(1) $1+2+3+4+5+\ldots+97+98+99+100$}

Den kommutative lov om addition siger at den rækkefølge hvori du lægger tallene sammen er vilkårlig, faktorerne kan bytte plads når du lægger dem sammen (commutare, lat. ombytning). Den associative additionslov siger at faktorerne som skal lægges sammen kan blive vilkårligt underordnet inden for parenteser og associeres på en hvilken som helst måde. I stedet for

' $1+2+3+4+5$ ' kunne vi skrive ' $(1+2)+(3+4)$ ' eller ' $1+(2+3)+4$ '

Derfor kan talrækken (1), ved at bytte pladser og grupperinger, også skrives på en anden måde således at, i stedet for den sekventielle orden, det første og det sidste tal, det andet og det næstsidste osv. kan blive sammenstillet og gjort til dele af en gruppe som er holdt sammen af parentesen.

(2) $(1+100)+(2+99)+(3+98)+\ldots+(49+52)+(50+51)$

Det som bliver åbenlyst ved denne operation er, at summen af hver parentes er den samme, nemlig 101.

(3) $(101)+(101)+\ldots+(101)+(101)$

Af dette følger at hvis vi har 50 sådanne parenteser, må regnestykket 101x50 udregnes. Således er 5050 den sum Gauss som en lille dreng beregnede på et par minutter. Og hvis vi skriver dem ned, den ene under den anden:

$$
\begin{aligned}
& \text { (4) } 1+100=101 \\
& 2+99=101 \\
& 3+98=101 \\
& \text {.. } \ldots \text {... } \\
& 49+52=101 \\
& 50+51=101 \\
& 5050
\end{aligned}
$$


Tricket med denne opdagelse af den matematiske formel for addition ligger i opbrydningen af sekventialiteten i den 'naturlige' rækkefølge af talsekvensen: kæden på 100 faktorer forvandles til en kxde med kun 50. Gennem denne omstrukturering af et aritmetisk udtryk genereres en ny konfiguration, som åbner for en kognitiv aha-oplevelse, en pludselig indsigt: at hver af de nyligt skabte grupper har samme værdi: '101'. Bruddet med de skrevne tals strikse sekvens til fordel for en genmodellering hvori 'de sidste skal blive de første' forårsager en andring af aspekter i den form hvormed en numerisk serie optræder. I lighed med Gottlob Freges morgen- og aftenstjerne som modi hvori Venus fremtræder for det menneskelige øje (Frege 1892: 32), er der her forskellige modaliteter hvormed vi kan repræsentere og organisere de første 100 hele tal. For Frege er planeten Venus referencen, mens morgen- og aftenstjernen kaldes meningen ${ }^{7}$ (Frege 1892: 26). I vores aritmetiske operation forbliver referencen af summen den samme, men meningen - forstået som den specifikke udtryksform - har ændret sig. Denne 'opsættelse af mening' via 'lighed i reference,' er muliggjort gennem en ikke-lineær manipulering af et grafisk arrangement.

Siden vi nu har karakteriseret det skrevne tegns implicitte rumlighed, tager vi et nærmere kig på det skrevne ords grafisme.

\section{Grafisme}

Selvom der findes skrevne tekster som ikke primært retter sig mod optisk tilegnelse - tænk på computerens binære alfabet bestående af elektriske impulser, eller på Braille's blindeskrift - så inkarnerer den grafiske inskription hvad enten den er skåret ind i eller påført oven på en materiel overfalde, en paradigmatisk fremtrædelsesform typisk for skrevne tekster. Uden styringen af et skriveredskab og uden støtten fra det tilpassede materiale

\footnotetext{
7 O.A. Gottlob Freges artikel "Über Sinn und Bedeutung" er på dansk oprindeligt oversat som "Om mening og reference". Det bør bemærkes, at eftersom nærværende artikel er oversat fra engelsk og ikke tysk, kan en vis forvirring opstå, idet Krämer benytter den gængse engelske oversættelse af Freges 'Bedeutung', som er 'meaning', mens 'Sinn' oversættes med 'sense.' Således oversætter jeg ikke 'meaning' (Bedeutung) i Krämers engelske originaltekst med det danske 'mening', men derimod med 'reference', hvorimod 'sense'(Sinn) i oversættelsen bliver til 'mening.'
} 
som tillader os at påføre det skrift, kan der ikke eksistere nogen skreven tekst (Greber et al. (eds) 2002; Ehlich 2002).

Fra en palæontologisk synsvinkel var det vores oprejste, tobenede gang som befriede vores hænder og gjorde os i stand til at løfte blikket, og således skabe en ny relation mellem hånd og værktøj, og mellem ansigt og synsaktivitet (Leroi-Gourhan 1980). ${ }^{8}$ Grafisme opstår i kombinationen mellem den tegnende hånd og det læsende øje. Dette leder André Leroi-Gourhan til at antage at billedlige handlinger, såsom at tegne og producere samt at læse grafiske symboler, først opstod med homo sapiens der eksisterede intet sammenligneligt førhen (Leroi-Gourhan 1980: 238). Grundlaget for grafisme udgøres af stregen eller linjen, som, sammen med punktummet, udgør notationers elementære repertoire. Fænomenet krusedulleskrift er også oplysende, idet det demonstrerer den allestedsnærværende magt der ligger i at udføre grafiske operationer, selv hinsides konventionerne (Driesen 2012). At trække en streg er, på samme tid sporet af en kropslig bevægelse og en løsrevet, fri skitse. Vi designer en verden i skriften og i det vi gør det, bruger vi tegn som er strengt konventionelle; men denne nedskrevne verden er, nolens volens - som et spor af en bevægelse, eller en persons udtryk bærer af den personlige håndskrift og af sin forfatters unikke signatur (Böhm/Gätje 2014; Krämer 2014).

Vigtigheden af grafisme for vores kunstneriske og intellektuelle udvikling kan ikke undervurderes. At være i stand til at tale et sprog betragtes generelt som altafgørende for kulturen. Men evnen til grafisk og billedligt udtryk er lige så vigtigt som vores mundtlige evne. Og dette gælder a fortiori for vores kognitive præstationer og for de medier vi gør brug af i vores kognition. Allerede Leibniz understregede at 'tegnede og skrevne tegn' er uerstattelige når det kommer til tænkning og forståelse (Leibniz 1705). Et kort blik på videnskabelige publiceringsstrategier gør det tydeligt at disse ikke alene er afhængige af skrevne tekster, men også af tabeller, grafer, diagrammer og kort. Der ville ikke være nogen videnskab uden visualisering i skrift, billeder, grafer og diagrammer. Og dette gælder ikke alene for den generelle

8 Om forholdet mellem sprog og gestik, se Armstrong/Stokoe/ Wilcox 1995. 
præsentation og cirkulation af information, men også for den originale videnskabelige argumentations- og forskningsproces (Hoffmann 2008; Latour 1990).

Det er derfor begrebet 'grafisme' er et begreb som, på den ene side, understreger ligheden mellem skrevne tekster og andre former for grafisk repræsentation som udtrykkes prototypisk af kort, grafer og diagrammer; og på den anden side understreger den udforskende og kreative rolle, som skriften spiller - udover den blot repræsenterende rolle. Af de mange muligheder for kognitiv og æstetisk erfaring inden for grafisme, synes relationen mellem rum og tid at være en af de mest relevante. Det grafiske mærke er altid også en teknik til at rumliggøre temporale processer: lineære forløb krystalliseres til simultanitet. Og modsat, stabile skrevne strukturer kan gøres til flydende temporale processer. Dette sker når en tekst læses højt som en tale, når et partitur transformeres til opført musik, eller når et computerprogram bliver brugt. Grafisme oversætter tid til rum og rum til tid. Dette kan sagtens vise sig at være kernen til den effektivitet, som denne kulturtekniske praksis har vist sig at have.

\section{Fortolkelighed}

Det skrevne tegn lever i to verdner: det fremtræder empirisksensorisk som et 'mærke' der er situeret i tid og sted. Men under læsning forvandler det sig også til identifikationen af en type, et skematiseret mærke som ikke signalerer noget bestemt, men snarere noget generelt. Selv om den visuelle overflade fremstår afgørende, kan et grafisk mærke kun tælle som en form for skrift når det referer til noget uden for og ud over sig selv. I kontrast til almindelige poststrukturalistiske positioner, så eksisterer der et 'uden for teksten.' Denne ydre dimension kan referere til andre tekster, til talt sprog, men også til musikalske lyde, dansetrin, koncepter, tal, computerkommandoer, logiske operationer osv. Uden ekstern referent, uden semantik, er der ikke skrift, kun ornament. Og dog kræver læsning, afkodning og tolkning også altid at vi ignorerer det skrevnes empiriske sensualitet og konkrete æstetiske overskud. Både kalligrafi og andre stædige former for håndskrift undergraver denne skematiske maksime og 
fremmedgør den. Et skriftlignende fænomen uden en semantik kan være kunst men det er hverken et eksempel på skriften som medium eller som redskab.

Ikke desto mindre - og dette er min pointe - så afhænger de operationer vi udfører med skrevne tekster ofte af udsattelsen af deres tolkning. Materialiteten, synligheden og operativiteten af det skrevne tegn er i stand til at sikre den grafiske overflades relative autonomi i forhold til dets tolkelige indhold. Skriftens epistemiske potentiale drejer omkring den præmis at konstruktion og tolkning kan tage adskilte veje. Bare tænk på eksemplet med cifferet nul: ' 0 '. Længe før nogen havde opstillet en matematisk tolkning sådan som George Booles' 'tomme mængde' for tallet nul, blev det skrevne tegn ' 0 ' brugt i vellykkede udregninger (Kaplan 2001; Rotman 1987; Krämer 1988: 54-59). Vi behøver ikke vide hvad ' $O$ ' betyder, eller om det overhovedet er et tal, for at være i stand til at regne med det. Konstruktionen og brugen af skrevne tal foregår deres matematiske fortolkning. Det var først efter århundreder hvor titalssystemet havde været i brug og fungeret effektivt at en helt ny forståelse af tal opstod: Et talbegreb blev skabt, som adskiller tal fra deres tælbarhed, fra forståelsen af dem som entiteter, der kan tælles.

Den kreative dimension $i$ at bortse fra mening findes ikke kun inden for matematikken. Også poesi lever af muligheden for opsættelse og udsættelse af mening. Kun fordi de skrevne ord $i$ et digt er sat sammen i usædvanlige og innovative konstellationer, er poesi i stand til at 'befri' sproget, så det får et eget liv, som ofte aldrig er hørt før. De formelle og poetiske udnyttelser af det skrevne ord trækker således begge på formens suverænitet over indholdet i skriften.

\section{Mekaniserbarhed}

Denne formens suverænitet over for indholdet indikerer en mekanisk kerne i skriftens brug. Det er ikke noget tilfælde at introduktionen af det indisk-arabiske talsystem med skrevne tegn producerede den første mekaniske regnemaskine, idet konfigurationer af ciffertegnene kunne inkarneres gennem mekaniske 
positioner (Krämer 1988; Künzel/Bexte 1993, 1996). Computeren - som i dag især bruges som netværk til kommunikation samt til visualisering og simulation - er og vedbliver at være en tekstbaseret maskine (Bolter 1991, 1997; Hayles 2000). Ordet 'gramma' græsk for 'bogstav,' minder os om programmeringens skriftlige natur. Ikke alene at skrive, læse og regne, men også programmering repræsenterer brugen af manuskript som en kulturteknik (Bolter 2005). Kun det binære alfabet som blev opfundet af Leibniz (Leibniz: 1705), og som for mennesker er både forvirrende og uudsigeligt at benytte som beregningsværktøj, muliggør digitaliseringen af vores kultur i betydningen af at forberede maskiner på at lave et medium om til et andet. Computeres aktiviteter er baserede på en overførsel af skrevne strukturer til operationer udført af elektriske impulser, som er usynlige for det menneskelige øje. Uden den synoptiske præsentation af digitaliserede dataproduktioner på computerskærmens flade samtidighed ville denne teknik imidlertid køre til ingen nytte.

Skriften får et nyt karaktertræk i vores digitale kultur. Det begynder med stregkoden, som identificerer ting med henblik på at introducere dem og implementere dem i en virtuel verden. Det er den særlige kvalitet ved digitaliseret brug af skrift at tidslighed kan overføres til skrevne teksters rumlige konfigurationer. Når vi skriver og læser gør vi normalt noget med de skrevne tegn og derfor har vi brug for at de er stabile. Men computerens 'auto-operative' skrift ${ }^{9}$ handler autonomt, dog naturligvis inden for en given programmeret ramme for aktion og reaktion. Som konsekvens af dette indtager de symbolske strukturer en mere dynamisk form, som er prototypisk realiseret i computersimuleringer (Gramelsberger 2010: 255-275). Desuden møder vi den digitale skrifts selv-operative kvalitet i 'linket', som er et fænomen, der giver os adgang til internettets bredt forbundne dataunivers. Kort sagt: indtil computerens tidsalder repræsenterede skrevne tekster en kulturteknik til rumlig strukturering af information; hvad der bliver mere og mere klart nu er imidlertid at skriften i den digitale sfære er avanceret til en kulturteknik,

9 Dette begreb diskuteres af Grube 2005. 
der strukturerer information temporalt. Forbindelsen mellem rum og tid i den digitale skrift er meget mere kompliceret. Men implementeringen af den tidslige operativitet i det der nedfældes på skrift er et bemærkelsesværdigt nyt stadie i skriftens udviklingshistorie.

\section{Konklusion}

'Notationel ikonicitet' er et strategisk begreb. Det tjener til at suspendere den reduktionisme som er implicit i den skrevne tekst forstået som nedskrevet sprog, til fordel for et skriftbegreb som er uafhængigt af det talte sprog. Det har til formål at vende sig bort fra en udbredt holdning inden for humaniora: Tendensen til at opdele vores symbolske færdigheder i to adskilte sfærer, en sproglig og en billedlig. Alligevel er det at erkende inskriptioners aflæselighed og operativitet ikke det samme som at befri skriften fra den sproglige diskurs og allokere den til billedernes diskurs. At inskription er visuel betyder således ikke at skrift er et billede. Vi ønsker ikke at introducere en 'ikonisk vending' i debatten om skrift. Dette af den grund, at der kan sås megen tvivl omkring hvorvidt der overhovedet eksisterer sådan noget som et "rent sprog" eller et "rent billede".

Hvad som giver mening metodisk er at lade begreberne "sprog" og "billede" markere de to yderpunkter i en skala, mellem hvilke næsten alle vores symbolske bedrifter kan lokaliseres som blandingsfenomener i forskellige grader af diskursivitet og ikonicitet. Afgørende for det diskursive perspektiv, er skriftens distinkthed og dens syntaktiske beskaffenhed, såvel som dens evne til at repræsentere noget. Dog behøver denne repræsenterende evne ikke at være noget sprogligt: det kunne også være tal, musikalske lyde, maskinkommandoer, logiske enheder, kemiske grundstoffer og dansetrin. For det ikoniske perspektiv gælder synligheden og det todimensionelle samtidighedsprincip. I inskriptioner er udsigelsens og visningens modi forbundne; men den specifikke blanding af det sproglige og det ikoniske adskiller sig for hver type af skrift og må udfoldes hver for sig. Skrevne tekster følger ikke tvedelingen mellem at være enten sprog eller billede; som hybrider udtrykker de begge dele: noget som 
er både sprogligt og ikonisk. Begrebet 'notationel ikonicitet' orienterer sig efter den præmis at skriftens laboratorium kan frigøre kognitive og æstetiske processer og erfaringer, for hvilke der ikke eksisterer nogen modeller eller prototyper i hverken det rene sprogs eller den rene ikonicitets sfærer. 


\section{Referencer}

Assmann, Jan. 1992. Das kulturelle Gedächtnis: Schrift, Erinnerung und politische Identität in frühen Hochkulturen. München: Beck.

Böhm, Manuela og Olaf Gätje. 2014. "Handschreiben - Handschriften Handschriftlichkeit: Zu Praktiken, Materialität und Theorie des Schreibens mit der Hand". Osnabrücker Beiträge zur Sprachtheorie (OBST) 85.7-22.

Bolter, Jay D. 1991. The computer, hypertext and the history of writing. Hillsdale, NJ: Erlbaum Association.

Bolter, David J. 1997. "Das Internet in der Geschichte der Technologien des Schreibens". Mythos Internet. Stefan Münker og Alexander Roesler (red.), 37-55. Frankfurt am Main: Suhrkamp.

Bolter, David J. 2005. "Digitale Schrift". I: Schrift: Kulturtechnik zwischen Auge, Hand und Maschine. Gernot Grube, Werner Kogge og Sybille Krämer (red.), 453-468. Paderborn, München: Fink.

Brandstetter, Gabriele, Franck Hofmann og Kirsten Maar. 2010. Notationen und choreographisches Denken. Freiburg i. Br., Berlin, Wien: Rombach.

Campe, Rüdiger. 1991. "Die Schreibszene. Schreiben”. I: Paradoxien, Dissonanzen, Zusammenbrüche: Situationen offener Epistemologie. Hans U. Gumbrecht og Karl L. Pfeiffer (red.), 759-772. Frankfurt am Main: Suhrkamp.

Cancik-Kirschbaum, Eva. 2005. "Beschreiben, Erklären, Deuten: Ein Beispiel für die Operationalisierung von Schrift im alten Zweistromland". I: Schrift: Kulturtechnik zwischen Auge, Hand und Maschine. Gernot Grube, Werner Kogge og Sybille Krämer (red.), 399-411. Paderborn, München: Fink.

Cancik-Kirschbaum, Eva og Bernd Mahr. 2005. "Anordnung und ästhetisches Profil". I: Bildwelten des Wissens: Kunsthistorisches Jahrbuch für Bildkritik, Diagramme und bildtextile Ordnungen, Horst Bredekamp og Gabriele Werner (red.), 96-114. Berlin: Akademie Verlag.

Coulmas, Florian. 1981. Über Schrift. Frankfurt am Main: Suhrkamp. Coulmas, Florian. 1993. "Das ABC der Wissenschaft". Merkur 3: 390398.

Damerow, Peter. 1993. "Buchhalter erfanden die Schrift". Rechtshistorisches Journal 12: 9-35.

Driesen, Christian, red. 2012. Über Kritzeln: Graphismen zwischen 
Schrift, Bild, Text und Zeichen. Zürich: Diaphanes.

Ehlich, Konrad. 1994. "Funktion und Struktur schriftlicher Kommunikation". I: Schrift und Schriftlichkeit. Ein interdisziplinäres Handbuch internationaler Forschung, Hartmut Günther og Otto Ludwig (red.), 18-41. Berlin: de Gruyter.

Ehlich, Konrad. 2002. "Schrift, Schriftträger, Schriftform: Materialität und semiotische Struktur". I: Materialität und Medialität von Schrift. Erika Greber, Konrad Ehlich og Jan-Dirk Müller (red.), 91-112. Bielefeld: Aisthesis.

Ernst, Wolfgang og Friedrich A. Kittler (red.). 2006. Die Geburt des Vokalalphabets aus dem Geist der Poesie: Schrift, Zahl und Ton im Medienverbund. München: Fink.

Falk, Harry. 1990. "Goodies for India. Literacy versus Non-Literacy. The Great Divide". I: Modes of thought: Essays on Thinking in Western and Non-Western Societies red. af Ruth Finnegan og Robin Horton, 103-120.

Finnegan, Ruth. 1973. "Literacy and Non-Literacy: The Great Divide? Some Comments on the Significance of 'Literature' in Non-Literate Cultures". I: Modes of thought: Essays on thinking in Western and non-Western societies, Robin Horton og Ruth H. Finnegan (red.), 112-144. London: Faber.

Frege, Gottlob. 1962. "Über Sinn und Bedeutung”. I: Funktion, Begriff, Bedeutung: Fünf logische Studien, Günther Patzig (red.), 38-63. Göttingen: Vandenhoeck og Ruprecht.

Giuriato, Davide og Stephan Kammer. 2006. "Die graphische Dimension der Literatur? Zur Einleitung". I: Bilder der Handschrift: Die graphische Dimension der Literatur. Davide Giuriato og Stephan Kammer (red.), 7-24. Frankfurt am Main: Stroemfeld.

Giuriato, Davide, Martin Stingelin og Sandro Zanetti. 2008. Schreiben heisst: sich selber lesen: Schreibszenen als Selbstlektüren. München: Fink.

Gong, Yushu. 2009. "The Accounts of the Origin of Writing from Sumer, Egypt and China - A Comparative Perspective". Wiener Zeitschrift zur Kunde des Morgenlandes 99: 137-158.

Goody, Jack. 1968. Literacy in traditional societies. Cambridge: Cambridge U.P.

Goody, Jack. 1986. The logic of writing and the organization of society. 
Cambridge [Cambridgeshire], New York: Cambridge University Press. Gramelsberger, Gabriele. 2010. Computerexperimente: Zum Wandel der Wissenschaft im Zeitalter des Computers. Bielefeld: transkription. Greber, Erika. 2002. Textile Texte: Poetologische Metaphorik und Literaturtheorie: Studien zur Tradition des Wortflechtens und der Kombinatorik. Bd. 9. Köln: Böhlau.

Greber, Erika, Konrad Ehlich og Jan-Dirk Müller, red. 2002. Materialität und Medialität von Schrift. Bielefeld: Aisthesis.

Groß, Sabine. 1990. "Schrift-Bild: Die Zeit des Augenblicks". I: Zeit-

Zeichen: Aufschübe und Interferenzen zwischen Endzeit und Echtzeit, Georg C. Tholen og Michael O. Scholl. Weinheim (red.), Bundesrepublik Deutschland: VCH, Acta Humaniora.

Groß, Sabine. 1994. Lese-Zeichen: Kognition, Medium und Materialität im Leseprozess. Darmstadt: Wissenschaftliche Buchgesellschaft.

Grube, Gernot. 2005. "Autooperative Schrift - und eine Kritik der Hypertexttheorie". Schrift: Kulturtechnik zwischen Auge, Hand und Maschine, Gernot Grube, Werner Kogge og Sybille Krämer (red.), 81-114. Paderborn, München: Fink.

Grube, Gernot, Werner Kogge og Sybille Krämer, red. 2005. Schrift: Kulturtechnik zwischen Auge, Hand und Maschine. Paderborn, München: Fink.

Günther, Hartmut. 1995. "Die Schrift als Modell der Lautsprache”. Osnabrücker Beiträge zur Sprachtheorie (OBST) 51.15-32.

Günther, Hartmut og Otto Ludwig, red. 1994-1996. Schrift und Schriftlichkeit. Writing and its Use. Ein interdisziplinäres Handbuch internationaler Forschung. Berlin: de Gruyter.

Havelock, Eric A. 1976. Origins of western literacy: Four lectures delivered at the Ontario Institute for Studies in Education, Toronto, 25. marts, 26,27, 28, 1974. Toronto: Ontario Institute for Studies in Education.

Havelock, Eric A. 1986. The muse learns to write: Reflections on orality and literacy from antiquity to the present. New Haven: Yale University Press.

Hayes, Brian. "Gauss's Day of Reckoning”. American Scientist 2006:94, 137-158.

Hayles, Katherine. 2002. Writing machines. (= Mediawork pamphlet.) Cambridge, Mass. MIT Press. 
Hoffmann, Christoph. 2008. Daten sichern: Schreiben und Zeichnen als Verfahren der Aufzeichnung. Berlin: Diaphanes Verlag.

Hoffmann, Christoph. 2010. "Schreiben als Verfahren der Forschung". I: Experiment und Literatur: Themen, Methoden, Theorien, Michael Gamper (red.), 181-207. Göttingen: Wallstein-Verl.

Kaplan, Robert. 2000. The nothing that is: A natural history of zero. Oxford, New York: Oxford University Press.

Kittler, Friedrich. 2003. "Zahl und Ziffer". I: Bild, Schrift, Zahl, Sybille Krämer og Horst Bredekamp (red.), 193-204. München: Fink.

Klein, Wolfgang. 1985. "Gesprochene Sprache - Geschriebene Sprache". Zeitschrift für Literaturwissenschaft und Linguistik 59, 9-35. Klein, Ursula, Timothy Lenoir og Hans U. Gumbrecht. 2003. Experiments, models, paper tools: Cultures of organic chemistry in the nineteenth century, Stanford, Calif. Stanford University Press.

Koch, Peter. 2009. "Graphé: Ihre Entwicklung zur Schrift, zum Kalkül und zur Liste". I: Schrift, Medien, Kognition: Über die Exteriorität des Geistes, Peter Koch og Sybille Krämer (red.), 43-82. Tübingen: Stauffenburg.

Koch, Peter og Sybille Krämer, red. 2009. I: Schrift, Medien, Kognition: Über die Exteriorität des Geistes. Tübingen: Stauffenburg.

Koch, Peter og Wulf Oesterreicher. 1985. Sprache der Nähe - Sprache der Distanz: Mündlichkeit und Schriftlichkeit im Spannungsfeld von Sprachtheorie und Sprachgeschichte. (= Romanisches Jahrbuch 36, s. 15-43.)

Krämer, Sybille. 2014. "Trace, Writing, Diagram: Reflections on Spatiality, Intuition, Graphical Practices and Thinking”. I: The power of the image: Emotion, expression, explanation. András Benedek, Kristóf Nyiri (red.), Peter Lang GmbH, Frankfurt am Main 2014, 3-22.

Krämer, Sybille, red. 2004. Performativität und Medialität. München: Fink.

Krämer, Sybille. 1988. Symbolische Maschinen: Die Idee der Formalisierung in geschichtlichem Abriss. Darmstadt: Wissenschaftliche Buchgesellschaft.

Krämer, Sybille. 1996. "Sprache und Schrift oder: Ist Schrift verschriftete Sprache”. Zeitschrift für Sprachwissenschaft 15, 1.92-112.

Krämer, Sybille. 2003a. "Kultur, Technik, Kulturtechnik". I: Bild, Schrift, 
Zahl, Sybille Krämer og Horst Bredekamp (red.), 11-22. München: Fink.

Krämer, Sybille. 2003b. "Writing, Notational Iconicity, Calculus: On writing as a Cultural Technique". I: Modern Languages Notes - German Issues, vol 118, No 3, 518-537 (tysk: ",Schriftbildlichkeit" oder: Über eine (fast) vergessene Dimension der Schrift”. Bild, Schrift, Zahl, Sybille Krämer og Horst Bredekamp (red.), 157-176. München: Fink).

Krämer, Sybille. 2004. "Friedrich Kittler - Kulturtechniken der Zeitachsenmanipulation". I: Medientheorien: Eine philosophische Einführung, Alice Lagaay og David Lauer (red.), 201-224. Frankfurt, New York: Campus.

Krämer, Sybille. 2005. "'Operationsraum Schrift': Über einen Perspektivenwechsel in der Betrachtung der Schrift". I: Schrift: Kulturtechnik zwischen Auge, Hand und Maschine, Gernot Grube, Werner Kogge og Sybille Krämer (red.), 23-60. Paderborn, München: Fink.

Krämer, Sybille. 2005. "Mündlichkeit/Schriftlichkeit”. I: Grundbegriffe der Medientheorie, Alexander Roesler og Bernd Stiegler (red.). Paderborn: Fink.

Krämer, Sybille. 2006. "Leerstellen-Produktivität". I: Instrumente in Kunst und Wissenschaft: Zur Architektonik kultureller Grenzen im 17. Jahrhundert, Helmar Schramm, Ludger Schwarte og Jan Lazardzig (red.), 502-526. Berlin, New York: Walter de Gruyter.

Krämer, Sybille. 2010. "Notationen, Schemata und Diagramme: Über ,Räumlichkeit' als Darstellungsprinzip. Sechs kommentierende Thesen". I: Notationen und choreographisches Denken, Gabriele Brandstetter, Franck Hofmann og Kirsten Maar (red.), 29-46. Freiburg i. Br., Berlin, Wien: Rombach.

Krämer, Sybille. 2012. "Punkt, Strich, Fläche: Von der Schriftbildlichkeit zur Diagrammatik”. I: Schriftbildlichkeit: Wahrnehmbarkeit, Materialität und Operativität von Notationen. Sybille Krämer, Eva Cancik-Kirschbaum og Rainer Totzke (red.), 79-100. Berlin: Oldenbourg Wissenschaftsverlag $\mathrm{GmbH}$.

Krämer, Sybille. 2014. “Über die Handschrift: Gedankenfacetten”. Osnabrücker Beiträge zur Sprachtheorie (OBST) 85.23-34.

Krämer, Sybille og Horst Bredekamp, red. 2003. Bild, Schrift, Zahl. München: Fink.

Krämer, Sybille, Eva Cancik-Kirschbaum og Rainer Totzke, red. 2012. 
Schriftbildlichkeit: Wahrnehmbarkeit, Materialität und Operativität von Notationen. (= Schriftbildlichkeit, 1.) Berlin: Oldenbourg Wissenschaftsverlag $\mathrm{GmbH}$.

Krämer, Sybille og Mareike Giertler, red. 2011. Schriftbildlichkeit. München.

Krämer, Sybille og Mareike Giertler. 2011. "Schwerpunkt ,Schriftbildlichkeit". Sprache und Literatur 42, 1. Halbjahr: 107.

Künzel, Werner og Peter Bexte. 1993. Allwissen und Absturz: Der Ursprung des Computers. Frankfurt am Main: Jüdischer Verl.

Künzel, Werner og Peter Bexte. 1996. Maschinendenken, Denkmaschinen: An den Schaltstellen zweier Kulturen. Frankfurt am Main: Insel.

Latour, Bruno. 1990. "Drawing Things Together". Representation in scientific practice, Michael Lynch og Steve Woolgar (red.), 19-68. Cambridge, Mass. MIT Press.

Leibniz, Gottfried Wilhelm. 1705., Explication de l'Arithmetique Binaire". I: Histoire de l'academie Royale des Sciences Paris 1705 (genoptrykt: Herrn von Leibniz Rechnung mit Null und Eins, udgivet af Siemens Aktiengesellschaft Berlin München 1979, 3. oplag.).

Leroi-Gourhan, André. 1980. Hand und Wort: Die Evolution von Technik, Sprache und Kunst. Frankfurt am Main: Suhrkamp.

Lüdeking, Karlheinz. 2006. "Bildlinie/Schriftlinie". Grenzen des Sichtbaren, Karlheinz Lüdeking (red.), 144-158. München: Wilhelm Fink.

Lüdtke, Helmuth. 1969. "Die Alphabetschrift und das Problem der Lautsegmentierung". Phonetik 20, 147-176.

Magnus, David. 2011. "Transkription und Faktur musikalischer Zeichen bei Anestis Logothetis". Schriftbildlichkeit, Sybille Krämer og Mareike Giertler (red.), 81-92. München.

Mersch, Dieter. 2005. "Die Geburt der Mathematik aus der Struktur der Schrift". Schrift: Kulturtechnik zwischen Auge, Hand und Maschine. Gernot Grube, Werner Kogge og Sybille Krämer (red.), 211-236. Paderborn, München: Fink.

Mersch, Dieter. 2012. "Schrift/Bild - Zeichnung/Graph - Linie/Markierung. Bildepisteme und Strukturen des ikonischen ,Als". Schriftbildlichkeit: Wahrnehmbarkeit, Materialität und Operativität von Notationen, Sybille Krämer, Eva Cancik-Kirschbaum og Rainer Totzke (red.), 305-328. Berlin: Oldenbourg Wissenschaftsverlag GmbH.

Olson, David R. 1991. "Literacy as Metalinguistic Activity". Literacy and 
orality, David R. Olson og Nancy Torrance (red.), 251-270. Cambridge, New York: Cambridge University Press.

Ong, W. J. 1982. Orality and Literarcy: The Technologizing of the Word. London/New York.

Parry, Milman. 1971. The making of Homeric Verse, I: The collected papers of Milman Parry, Oxford: Clarendon Pr.

Raible, Wolfgang. 1991. Die Semiotik der Textgestalt: Erscheinungsformen und Folgen eines kulturellen Evolutionsprozesses. Heidelberg: C. Winter.

Raible, Wolfgang. 1993. "Die Entwicklung ideographischer Elemente bei der Verschriftlichung von Wissen". I: Vermittlung und Tradierung von Wissen in der griechischen Kultur, Wolfgang Kullmann og Jochen Althoff (red), 15-37. Tübingen: G. Narr.

Raible, Wolfgang. 2004. "Über das Entstehen der Gedanken beim Schreiben". Performativität und Medialität, Sybille Krämer (red.), 191-214. München: Fink.

Raible, Wolfgang. 2009. "Von der Textgestalt zur Texttheorie. Beobachtungen zur Entwicklung des Text-Layouts". Schrift, Medien, Kognition: Über die Exteriorität des Geistes. Peter Koch og Sybille Krämer (red.), 29-42. Tübingen: Stauffenburg.

Rheinberger, Hans J. 1999. "Alles, was überhaupt zu einer Inskription führen kann”. Wissensbilder: Strategien der Überlieferung, Ulrich Raulff og Gary Smith (red.), 265-277. Berlin: Akademie Verlag. Roy, Harris. 1990. "On Redefining Linguistics". I: Redefining linguistics red. af Hayley G. Davis og Talbot J. Taylor, 18-52. London, New York: Routledge.

Schmandt-Besserat, Denise. 1992. Before writing. Austin: Univ. of Texas Pr.

Schröter, Jens. 2004. "Intermedialität, Medienspezifik und die universelle Maschine". I: Performativität und Medialität, Sybille Krämer (red.). München: Fink.

Stingelin, Martin. 1999., Unser Schreibzeug arbeitet mit an unseren Gedanken: Die poetologische Reflexion der Schreibwerkzeuge bei Georg Christoph Lichtenberg und Friedrich Nietzsche, I LichtenbergJahrbuch 1999 [2000], 81-98.

Summers, David. 2003. Real spaces: World art history and the rise of Western modernism. London, New York, NY: Phaidon Press. 
Wilcke, Claus. 2000. Wer las und schrieb in Babylonien und Assyrien: Überlegungen zur Literalität im Alten Zweistromland. München: Verlag der Bayerischen Akademie der Wissensschaften.

Zanetti, Sandro, red. 2012. Schreiben als Kulturtechnik: Grundlagentexte. Berlin: Suhrkamp.

Zumthor, Paul. 1984. La poésie et la voix dans la civilisation médiévale. (= Essais et conférences / Collège de France.) Paris: Presses universitaires de France. 